\title{
Melatonin - A Cutaneous Perspective
}

\author{
Mona Sharma' ${ }^{1}$, Priyanka Hemrajani' ${ }^{1}$ Tapan Kumar Dhali ${ }^{1}$
}

${ }^{1}$ Department of Dermatology, Venereology, and Leprosy, PGIMSR \& ESI Model Hospital, Basaidarapur, New Delhi 110015

\begin{abstract}
Melatonin (MLT) is an endogenous hormone secreted from the pineal gland, located deep in the brain in the epithalamus associated with numerous biological activities. The primary function of melatonin is to regulate sleep-wake cycles. However, research over the last few years has enlightened a range of functions associated with this molecule, including anti-inflammatory, direct and indirect antioxidant activity, regenerative tissue benefits, and preservation of mitochondrial function. Melatonin's anti-inflammatory and antioxidant support, coupled with its mitochondrial modulation, makes it a vital molecule to use for skin health homeostasis. The cutaneous melatoninergic system's widespread expression and pleiotropic activity provides for a high level of cell-specific selectivity. Several skin cells, including normal and malignant keratinocytes, melanocytes, fibroblasts and hair follicles, express melatonin receptors. Melatonin also has receptor-independent effects that protect against oxidative stress and can reduce ultraviolet radiation-induced damage. Several functions of melatonin in the skin have been experimentally implicated such as hair growth cycling, fur pigmentation, melanoma control, suppression of ultraviolet-induced damage to the skin cell. Melatonin may play a role in treating several dermatoses e.g., atopic eczema, psoriasis, melasma, ulcer healing, and malignant melanoma. There is a plethora of functional melatonin properties, which still await to be fully appreciated by dermatologists. The current review emphasizes few of the established uses and few emerging potentialities that render melatonin a promising candidate for managing several diseases.
\end{abstract}

Key words: Anti-oxidant; Melatonin; Photoprotection; Skin

\section{Introduction}

$\mathrm{M}$ elatonin, an evolutionarily ancient derivative of serotonin with hormonal properties, is the primary neuroendocrine secretory product of the pineal gland. It is an endogenous neuroendocrine hormone and is a well-known pleiotropic regulator of the circadian rhythm. The most accepted role of melatonin is its involvement in the regulation of the sleep-wakeup cycle. It is a methoxyindole ( $\mathrm{N}$-acetyl 5 methoxytrytamine) primarily produced by the pineal gland from tryptophan via serotonin. It is also synthesized in various extrapineal sites such as lungs, liver, kidney, brain, harderian gland, retina, cochlea, ciliary body, bone marrow, immune cells,

Funding: No

Conflict of Interest: No

\section{Address of Correspondence}

Prof. Dr. Tapan Kumar Dhali

ORCID ID: 0000-0003-0378-9003

Dept. of Dermatology, Venerology and Leprosy, PGIMSR \& ESI Model Hospital, Basaidarapur, New Delhi - 110015, Phone number 9990724083 ,

E-mail: tapan99@gmail.com lens, endothelial cells, thyroid, pancreas, thymus, gastrointestinal tract, spleen, placenta, gonads, and skin. ${ }^{1}$ It is metabolized by the liver as well as peripheral organs, including the skin.

Melatonin has numerous functions, which are taxon, species and tissue specific to various bacteria, fungi, eukaryotes, plants; vertebrates, and invertebrates which produce it. In humans, melatonin orchestrates numerous complex cell responses, ${ }^{1,2}$ directly and indirectly, apart from sleep regulation due to its anti-inflammatory, anti-ageing, anti-oxidant, anti-

\section{Date of Submission: $19^{\text {th }}$ June, 2021 \\ Date of Acceptance: 30 $0^{\text {th }}$ August, 2021 \\ Date of Publication: $1^{\text {st }}$ October 2021}

How to cite this article

Sharma M, Hemrajani P, Dhali TK. Melatonin - A Cutaneous Perspective. NJDVL 2021;19(2):3-12. https://doi.org/10.3126/ njdvl.v19i2.39452.

\section{(c) (i)}

Licensed under CC BY 4.0 International License which permits use, distribution and reproduction in any medium, provided the original work is properly cited. 
tumour, thermoregulatory, radioprotective and immunomodulator properties. Rather, the idea of supplementing melatonin in the advanced aged population to protect brain health arises after discovering its antioxidant properties. Similarly, research has elucidated melatonin as a protective agent against ischaemia reperfusion injury in the brain, heart, and liver. ${ }^{3}$ Melatonin and its metabolites have emerged as indispensable for physiological skin functions and adequate protection of cutaneous health from hostile environmental factors. Its cutaneous effects are a consequence of its local concentration, metabolic consumption, and generation of metabolites with potentially diverse phenotypic activities acting through receptor-dependent and independent mechanisms. Mammalian skin transforms L-tryptophan to melatonin through serotonin and n-acetyl serotonin (NAS intermediates). Human scalp hair follicles also synthesize and secrete it in vitro, and this process is upregulated by norepinephrine. Melatonin and its metabolites act as free radical scavengers and protectors against oxidative stress. Melatonin also regulates mitochondrial functions that maintain cutaneous cellular homeostasis.

\section{Melatonin synthesis in skin}

Aaron Lerner hypothesized that melatonin release in the skin might lead to pigmentary disorders. The earliest documentation of melatonin synthesis in the skin was done by Slominski et al., wherein biotransformation of $[3 \mathrm{H}]$ serotonin by cultured hamster skin to $3 \mathrm{H}$-metabolites corresponding to $\mathrm{N}$-acetylserotonin (NAS), melatonin, and 5-methoxytryptamine (5-MT) was demonstrated. ${ }^{4}$

Follow-up studies on rodent, and human hair follicles proved that keratinocytes, melanocytes, and melanoma cells are capable of endogenous melatonin production. Mammalian skin transforms L-tryptophan to melatonin through serotonin and $n$-acetyl serotonin (NAS intermediates). Skin cells express tryptophan hydroxylase type 1 (TPH1; all resident cells), TPH2 (melanocytes), as well as enzymes necessary for acetylation of serotonin such as arylalkylamine-Nacetyl- transferase/serotonin $\mathrm{N}$-acetyltransferase (SNAT), arylamine-N actyltransferase (AANAT), hydroxyindole-Omethyltransferase/ $\mathrm{N}$-acetylserotonin methyltransferase (HOMT/NASMT). The rate-limiting enzyme of melatonin synthesis is AANAT/SNAT. Human scalp hair follicles also synthesize and secrete it in vitro, and this process is upregulated by norepinephrine. Skin expression of membrane-bound melatonin receptors MT1(in the epidermis) and MT2 (in adnexal structures) varies among species, and consequently, melatonin levels vary depending on environmental factors (UVB), underlying pathology (skin cancer), age, race, genetic background. ${ }^{5}$ The highest melatonin concentration was found among Afro-Americans.

\section{Melatonin metabolism}

Studies on human immortalized epidermal keratinocytes ( $\mathrm{HaCaT}$ ) have shown that both indolic and kynuric pathways metabolize melatonin, and this metabolism is stimulated by UVB. Several metabolites are generated in the epidermis, such as 6-hydroxymelatonin (major metabolite), 5-methoxytryptamine,5-methoxytryptophol, AFMK, N1-acetyl-5-methoxykynuramine (AMK). These potentially affect mitochondrial functions and consequently the skin phenotype. ${ }^{6}$

\section{Melatonin-mitochondria axis}

Melatonin metabolism in mammals occurs through complexpathways associated with cytosol, endoplasmic reticulum (microsomes), and mitochondria. In mitochondria, melatonin is metabolized through monooxygenase (the cytochrome P450 dependent pathway) and peroxidase (the kynuric pathway). The kynuric pathway involves pseudo-peroxidase activity of cytochrome $\mathrm{c}$ in the presence of $\mathrm{H}_{2} \mathrm{O}_{2}$. This converts melatonin into AFMK and its secondary product, AMK, via sequential steps that generate 2-hydroxymelatonin and 2,3-dihydroxymelatonin as intermediates which not only compensate for the absence of the conventional H2O2-detoxifying enzymes (catalase, glutathione peroxidase, and peroxiredoxin III) in the intermembranous space but also contribute to the neutralization of ROS. Similarly, cytochrome P-450dependent 6-hydroxylation and O-demethylation of melatonin provide mitochondria with target compounds that maintain mitochondrial homeostasis. It has been suggested that melatonin could donate electrons to the ETC, thus improving mitochondrial respiration and increasing ATP production. Such electron transfer in the terminal cytochrome $c$ oxidase segment of the ETC is crucial considering agerelated decline in complex II (succinate: ubiquinone oxidoreductase) activity in human skin fibroblasts. Melatonin thus plays a significant role in mitochondrial bioenergetics and homeostasis (including biogenesis, fission, fusion, mitophagy), and the skin protective activities of melatonin (both direct and indirect) are dependent on mitochondria through the reciprocal interactions with skin cell homeostasis. ${ }^{7}$ 


\section{Role of Melatonin In Skin}

The role of melatonin, its precursors, and metabolites in the regulation of physiological functions of the skin and its attenuating effects in skin pathology has been extensively reviewed in recent times. Melatonin can regulate cutaneous adnexal, pigmentary, barrier, and oncostatic functions. Various functions of melatonin have been tabulated. (Table 1)

\section{Functions of melatonin}

\section{Table 1}

\begin{tabular}{|c|c|}
\hline $\begin{array}{l}\text { Cutaneous specific } \\
\text { functions }\end{array}$ & Other Functions \\
\hline $\begin{array}{ll}\text { - } & \text { Photoprotective } \\
\text { - } & \text { Anti-oxidant } \\
\text { - } & \text { Anti-inflammatory } \\
\text { - } & \text { Hair growth \& } \\
& \text { pigmentation } \\
\text { - } & \text { Skin lightening } \\
\text { - } & \text { Regulation of barrier } \\
& \text { function } \\
\text { - } & \text { Thermoregulation } \\
\text { - } & \text { Regulation of skin } \\
& \text { immune system } \\
\text { - } & \text { Anti-vesicant action }\end{array}$ & $\begin{array}{ll}\text { - } & \text { Circadian pacemaker } \\
\text { - } & \text { Mitochondrial } \\
\text { - } & \text { DNAmeostasis } \\
\text { - } & \text { Tisti-apoptotic } \\
& \text { \& repair } \\
\text { - } & \text { Anti-tumour } \\
\text { - } & \text { Immunomodulation } \\
\text { - } & \text { Radioprotective } \\
\text { - } & \text { Angiogenesis } \\
\text { - Sexual maturation }\end{array}$ \\
\hline
\end{tabular}

\section{Photoprotection}

Acute exposure to UVR may cause photodamage in human skin characterized by erythema, edema, pain, pruritus, tanning, etc., whereas chronic exposure may lead to carcinogenesis and skin ageing. ${ }^{7}$ Melatonin is a highly lipophilic molecule, which can penetrate organic membranes. It absorbs UV light in the 225$275 \mathrm{~nm}$ wavelength range, much lower than normal UVA and UVB wavelengths. It inhibits UV-induced lipid peroxidation of membranes, thereby decreasing arachidonic acid metabolites such as prostaglandins and leukotrienes. The role of topically applied melatonin has been studied extensively in the attenuation of skin erythema in healthy human subjects exposed to either artificial UVR or natural sunlight, thus demonstrating melatonin's clinical potential as a protector against photodamage..$^{8-11}$ Melatonin is a free radical scavenger, that quenches free radicals involved in cell damage, the most notorious being nitric monoxide (NO-) and $\mathrm{OH}$ free radical. Several studies have confirmed the protective effects of melatonin and its metabolites:6hydroxymelatonin, AFMK, N-acetyl-serotonin, and 5-methoxytryptamine against oxidative cell damage in human skin cells, namely keratinocytes, melanocytes, and dermal fibroblasts. ${ }^{12-14}$ These also play a role in cellular defense against oxidative damage by promoting glutathione production and enhance activities of other anti-oxidant enzymes: superoxide dismutase (SOD), catalase (CAT), and glutathione peroxidase (Gpx). Melatonin also prevents UVB-driven anti-oxidative enzyme depletion, including SOD1, catalase, and GPx in the human skin. Melatonin and its metabolites reduce the levels of the UVB-induced cell damage and enhance UVB-induced DNA repair in keratinocytes and melanocytes. The proposed underlying mechanism involves the stimulation of phosphorylation of tumour suppressor protein p53 and enhancement of nucleotide excision repair (NER) via interactions between damaged DNA and the NER core factors XPC and XPA. Recent studies have implicated that nuclear euthyroid 2 related factors 2 and sirtuin (sirt1) are significant regulators in oxidative stress response and skin ageing. ${ }^{15,16}$ Melatonin or its metabolites have a crucial role in activating these nuclear factor erythroid 2-like 2 (NRF2) and upregulation of NRF2-dependent pathway in melanocytes and in activation of phase2 antioxidant enzymes ( $\gamma$-GCS, HO-1, NQO1) in ultraviolet radiation-treated normal human epidermal keratinocytes. ${ }^{12,16}$

\section{Anti Ageing}

Skin ageing is due to several intrinsic and extrinsic factors, with decreased mitochondrial function as a significant underlying mechanism. UV light is a principal extrinsic agent which causes a decrease in collagen in the dermal extracellular matrix and DNA alterations (thymine-thymine dimer formation). ROS (reactive oxygen species) formation and oxidative stress cause damage to mitochondrial pathophysiology, inflammation, cytotoxicity, and resultant cell damage. Melatonin has potent, long lasting, indirect antioxidant action and stimulates transcription factor NRF2 (upregulation of gene expression) antioxidative enzymes in the skin such as $\mathrm{Cu}-\mathrm{Zn}$ superoxide dismutase, catalase, and glutathione peroxidase (Figure 1). It also downregulates interstitial collagenase MMP-1, stromelysin 1(MMP-3), stromelysin 2 (MMP10), aldehyde dehydrogenase 3 type $A 1$. As $90 \%$ of ROS is produced in mitochondria, melatonin has a significant role in anti-ageing therapy. ${ }^{17,18}$

The role for melatonin, vitamins D3, E, and C in the prevention and the treatment of oxidative stressinduced skin aging. (Courtesy- Bocheva G, Slominski RM, Slominski AT. Neuroendocrine Aspects of Skin Aging. Int J Mol Sci. 2019;20(11):2798) 


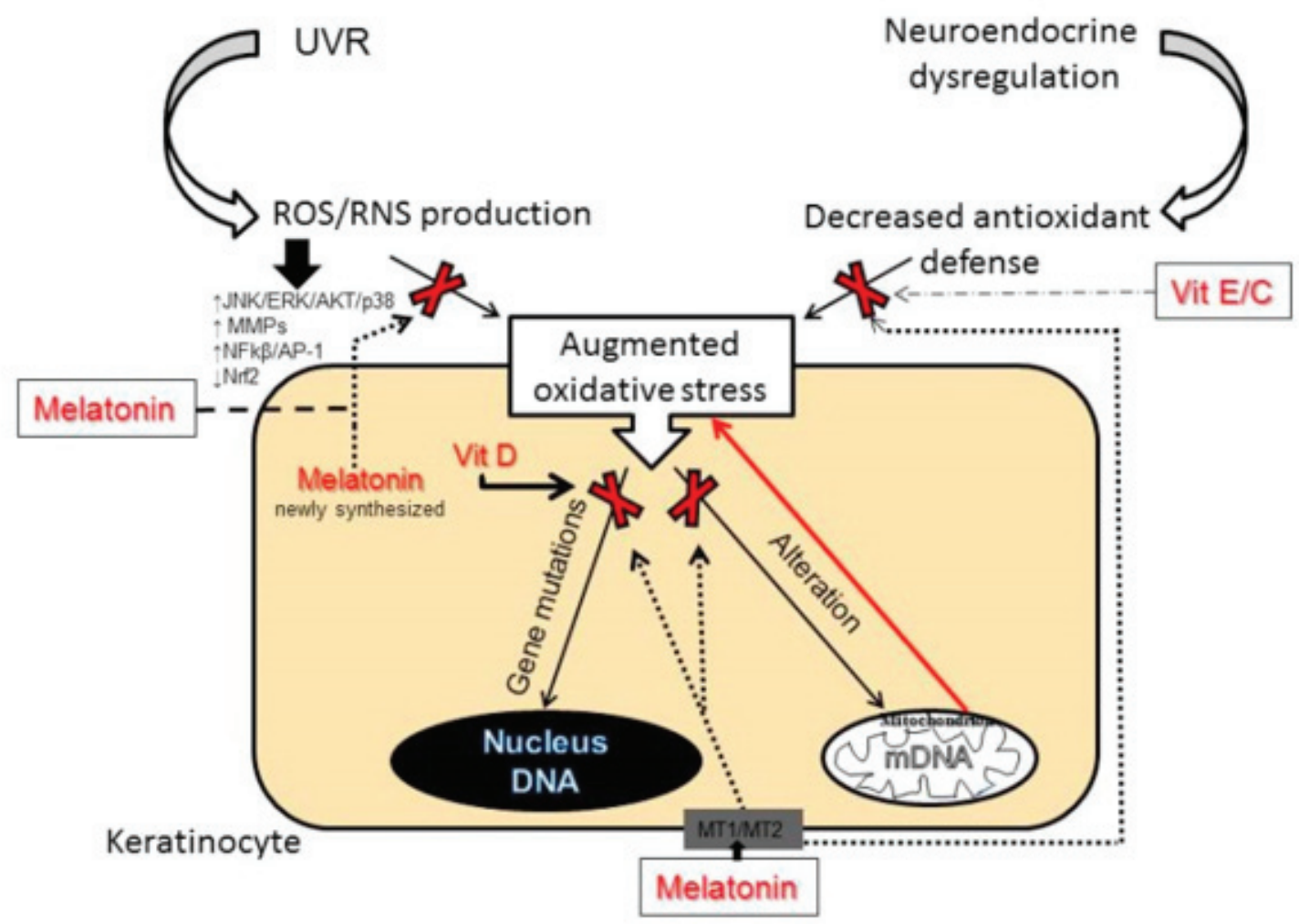

Figure 1: Role of Melatonin in Antiaging

\section{Anti-Apoptotic}

Keratinocyte proliferation provides an effective epidermal barrier in the skin which is known to be depleted due to UV-mediated mitochondrial dysfunction. The terminal deoxynucleotidyl transferase-mediated dUTP nick-end labeling (TUNEL) assay showed the inhibition of UV-induced apoptosis in human HaCaT keratinocytes. ${ }^{19}$ Melatonin is involved in a complex- and concentration-dependent regulation of mitochondrial homeostasis, widely known as a melatonin-mitochondrial axis in the skin as described in previous sections. ${ }^{20}$ Melatonin was found to inhibit cytochrome crelease from mitochondria and decrease activation of caspases 3, 7, and 9 suggesting inhibition of mitochondrial pathway of apoptosis. ${ }^{21-22}$ Apart from direct scavenging of reactive oxygen species, it also helps maintain optimal mitochondrial membrane potential $(\Delta \psi \mathrm{m})$. The suggested mechanism is direct, or receptor-mediated inhibition of the mitochondrial permeability transition pore (MPTP) and stimulation of uncoupling proteins (UCPs) which still requires further evaluation. It should be noted that melatonin and its metabolites would coordinate mitochondrial interactions with the skin cell to decide whether it survives or enters a precisely defined differentiation pathway, necessary for barrier formation, or dies through apoptotic pathways to prevent carcinogenesis.

\section{Anticancer}

Melatonin is nontoxic and exhibits a range of beneficial effects against cancer via apoptotic, anti-angiogenic, anti-proliferative, and metastasis-inhibitory pathways. Combining of melatonin with conventional drugs improves the drug sensitivity of cancers, including solid and liquid tumours. ${ }^{23-24}$

The anti-tumour property of melatonin has been well documented in several in vitro and in vivo models. ${ }^{25-}$

${ }^{27}$ Melatonin and its metabolites have been shown to inhibit cultured human melanoma cell growth, ${ }^{28-31}$ and attenuation of benzo(a)pyrene-induced cutaneous sarcomas, squamous cell carcinomas, and papilloma in mice models. ${ }^{32-34}$ Gadheri et al. found that patients with basal cell and squamous cell carcinomas had lower urinary indicators of systemic melatonin production than controls. ${ }^{35}$ Research has proved that melatonin inhibits melanoma growth and also melanin dispersion by reducing the levels of cyclic adenosine monophosphate (cAMP) and $\alpha$-melanocytestimulating hormone (MSH) apart from its antioxidant action against UV-induced free radicals. ${ }^{11}$ This activity depends on the level of expression of MT1 and MT2 receptors and melatonin-binding quinone reductase $\mathrm{NQO} 2$ in both skin cell lines as well as melanoma cell lines. ${ }^{36-37}$ Melatonin and its precursor $\mathrm{N}$-acetylserotonin 
bind to several regulatory proteins including quinone reductase 2. ${ }^{38-39}$ Quinone reductase 2, protects cells against oxidative stress in dimethylbenz(a)anthraceneinduced skin cancer and is required for tumour necrosis factor- $\alpha$-induced apoptosis in keratinocytes. ${ }^{40-41}$

Clinical trials have suggested the role of melatonin and its metabolites as an adjuvant in non-resectable lentigo maligna and mucosal melanomas. Melatonin has radioprotective effects, secondary to its action on the mitochondria or/and mitochondrial melatonin metabolism to a biologically active metabolite. This property may be used in chemotherapy, either to reduce its side effects or enhance its efficacy and in post lymph node resection disease-free survival period. Systematic clinical trials for the use of melatonin in cancer prevention and oncological therapies are the need of the hour as it is cost-effective, has favourable toxicological profile, and less adverse effects.

\section{Wound Healing}

Melatonin as a regulator of epidermal homeostasis has a positive impact on the proliferation of keratinocytes and also on the expression of involucrin, keratin-10, and keratin-14. ${ }^{42}$ According to a proposed novel melatonin-mitochondrial axis; melatonin regulates cell survival, terminal differentiation, and also apoptosis as a part of epidermal barrier function. This regulation of epidermal cell density and ROS scavenging action together helps in tissue repair and regeneration, thereby wound healing. Melatonin can regulate angiogenesis differently under different pathological and physiological conditions. In tumours, age-related ocular diseases, and in a hypoxic environments, melatonin inhibits neovascularization. This property can be utilized in the prevention of the initiation and development of atherosclerosis.

In contrast to this, it promotes angiogenesis in gastric ulcers, skin lesions, and some physiologic processes through regulation of vascular endothelial growth factor and its receptors and other specific regulatory mechanisms, thereby opening prospects of the therapeutic use of melatonin in gastroesophageal reflux disease (GERD) and peptic ulcer disease. ${ }^{43}$ Recent studies have also demonstrated the role of melatonin in wound healing. ${ }^{44-47}$ Further research on the beneficial role of melatonin and its metabolites on epidermal barrier formation and wound healing is warranted.

\section{Skin Pigmentation}

Skin pigmentation is due to several mechanisms that lead to increased melanin production /deposition and is influenced by age, hormonal imbalance, endocrine diseases, inflammatory diseases, photodamage, etc. Melatonin and its metabolites regulate circadian rhythm, melanogenesis, and melanocyte activities in the human epidermis. The use of melatonin in defined circadian windows has shown its effectiveness in skin lightening. Topical melatonin has a protective action in vitiligo due to the amelioration of oxidative stress environment. ${ }^{48-49}$ Since melatonin plays a role in the reproductive cycle of other animals by modulation of estrogen and progesterone, it may also help reduce hyperpigmentation seen in diseases where a hormonal component is involved in the pathophysiology, such as melasma. Topical melatonin alone, and combined with $4 \%$ hydroquinone and oral melatonin, were shown to significantly decrease the pigmentation in all melasma patients. It was found that combining topical melatonin 5\% with oral melatonin $3 \mathrm{~g}$ daily for 120 days decreases MASI significantly when compared to placebo..$^{50-51}$ It also caused an increase in glutathione levels and a decrease in malondialdehyde levels, showing alleviation in oxidative stress.

\section{Hair Growth and Pigmentation}

Hair follicles in the human scalp produce melatonin, and this synthesis is stimulated by noradrenaline. Melatonin is known to stimulate nuclear erythroid 2 related factor 2 , which protects against oxidative stress-induced hair damage. ${ }^{52,53}$ Kobayashi et al. found that melatonin renders human hair follicles ex vivo less susceptible to chemotherapy-induced damage. ${ }^{54}$ Studies have shown that topical melatonin has the potential to inhibit androgenetic alopecia in females as it downregulates expression of intrafollicular estrogen receptors and thus modulates human hair follicle responses to estrogens. Circadian clock proteins have been known to be involved in the control of human hair follicle cycling and hair cum skin pigmentation. ${ }^{55,56}$ Further research needs to be done on the impact of melatonin in hair growth and pigmentation through modulation of peripheral circadian activity in the skin.

\section{Inflammatory Dermatoses}

Melatonin has been known to have both immunostimulatory and anti-inflammatory actions. Key cells involved in innate immunity, such as mast cells, express melatonin receptors, and melatonin has a crucial role in T-cell-based immune pathologies. ${ }^{57,58}$ Skin disorders such as atopic dermatitis are accompanied by infiltration and activation of mast cells, releasing vasoactive and proinflammatory 
mediators. Melatonin inhibits the development of atopic eczema and reduces serum total IgE and IL-4. Disturbances in serum melatonin levels have been reported in patients with psoriasis, ${ }^{59}$ and beneficial effects of melatonin have been seen in atopic dermatitis, seborrhoeic dermatitis. ${ }^{60-61}$ Apart from the skin, several studies have proved that melatonin has a beneficial therapeutic value in the treatment of several inflammatory diseases, such as Alzheimer's, Amiotrophic Lateral Sclerosis, Multiple Sclerosis and Huntington's disease as well as other related disorders of mitochondrial dysfunction. ${ }^{62-63}$

\section{Thermoregulation}

Melatonin is important for skin homeostasis and can modify vasoconstrictor response to cooling and vasodilator response to heat. Through its circadian activity and even directly, it regulates the core body temperature and skin temperature. ${ }^{64}$

\section{Anti-Vesicant Action - Theory In Pipeline}

Vesicants or blistering agents are chemical warfare agents (CWAs) which cause blistering lesions in the skin and mucous membranes. These include sulphur mustards, nitrogen mustards, and lewisite. These cytotoxic alkylating agents were initially developed as chemical weapons to induce ocular, dermal, and respiratory damage. Melatonin has been proposed as a feasible agent to counteract the induced toxic damage and possible long-term effects of the most representative blister agents. It is a well-characterized antioxidant with anti-inflammatory and scavenger action, and recent studies have shown its ability as a promising epigenetic modulator suggesting its use as a therapeutic agent for the treatment against vesicant CWAs. ${ }^{65}$

\section{References}

1. Acuña-Castroviejo D, Escames G, Venegas C, Díaz-Casado ME, Lima-Cabello E. López LC, et al. Extrapineal melatonin: sources, regulation, and potential functions. J Cell Mol Life Sci. 2014 Aug; 71(16):2997-3025. https://doi.org/10.1007/ s00018-014-1579-2

2. Hardeland R, Cardinali DP, Srinivasan V, Spence DW, Brown GM, Pandi-Perumal SR. Melatonin, a pleiotropic, orchestrating regulator molecule. Prog Neurobiol. 2011 Mar; 93(3):350-84. https:// doi.org/10.1016/j.pneurobio.2010.12.004

\section{Role of Melatonin in Covid-19}

The potential role of melatonin in various viral infections such as Respiratory syncytial virus infection, Venezuelan equine encephalitis virus infection, viral hepatitis, viral myocarditis, Ebola virus, West Nile virus, Semliki Forest virus has been well documented. Recently, the COVID-19 pandemic has necessitated research for potential molecules. Cytokines, hyperinflammatory state, and lymphopenia play crucial roles in COVID-19 pathogenesis. The efficacy of melatonin in the regulation of the immune system has been shown in both in vivo and in vitro studies. Reiter et al. proposed that melatonin may be given consideration for prophylactic use or treatment alone or in combination with other drugs to combat Covid-19 owing to its multiple actions as an anti-inflammatory, anti-oxidant, and anti-viral (against other viruses) agent. ${ }^{66}$ Melatonin, like other immunomodulatory agents, may be used as an effective adjuvant besides vaccination to boost the vaccine's effectiveness in patients with both compromised and healthy systemic and cutaneous immune systems. ${ }^{67,68}$

\section{Conclusion}

Melatonin is a unique, essentially nontoxic, readily available molecule whose multifunctional aspects still lie unexplored. However, there is plenty of literature related to the beneficial actions of melatonin and its application in numerous diseases. Melatonin displays a significantly high antioxidative capacity, antiinflammatory actions, and recent studies have shown its ability as a promising epigenetic modulator. There is a need to reinstate the role of melatonin as a potential agent in various dermatological conditions, particularly those associated with substantive oxidative damage. Topical and transepidermal delivery of melatonin is a promising area for full exploration in future dermatotherapy and preventive cutaneous medicine.

3. Yang Y, SunY, Yi W, LiY,Fan C,Xin Z, Jian S, et al. A review of melatonin as a suitable antioxidant against myocardial ischemia- reperfusion injury and clinical heart diseases. I Pineal Res.2014;57(4):357-66. https://doi.org/10.1111/ jpi.12175

4. Slominski A, Baker J, Rosano TG, Guisti LW, Ermak G, Grande M, et al. Metabolism of serotonin to $\mathrm{N}$-acetylserotonin, melatonin, and 5-methoxytryptamine in hamster skin culture. J Biol Chem. 1996 May 24;271(21):12281-6. https://doi.org/10.1074/jbc.271.21.12281 
5. Fischer TW, Trueb RM, Hanggi G,Innocenti M, Elsnern P. Topical melatonin for treatment of androgenetic alopecia. Int. J Trichology, 2012;4(4):236-45. https://doi.org/10.4103/09747753

6. Slominski A, Tobin DJ, Zmijewski MA, Wortsman J, Paus R. Melatonin in the skin: synthesis, metabolism and functions. Trends Endocrinol Metab. 2008 Jan;19(1):17-24. https://doi. org/10.1016/j.tem.2007.10.007

7. Slominski AT, Zmijewski MA, Semak I, et al. Melatonin, mitochondria, and the skin. Cell Mol Life Sci. 2017;74(21):3913-25. https://doi. org/10.1007/s00018-017-2617-7

8. Scheuer C, Pommergaard HC, Rosenberg J, Gögenur I. Dose dependent sun protective effect of topical melatonin: A randomized, placebocontrolled, double-blind study. J Dermatol Sci. 2016 Nov;84(2):178-85. https://doi. org/10.1016/j.jdermsci.2016.08.007

9. Bangha E, Elsner P, Kistler GS. Suppression of UV-induced erythema by topical treatment with melatonin (N-acetyl-5-methoxytryptamine). A dose response study. Arch Dermatol Res. 1996 Aug; 288(9):522-6. https://doi.org/10.1007/ BF02505248

10. Fischer T, Bangha E, Elsner P, Kistler GS. Suppression of UV-induced erythema by topical treatment with melatonin. Influence of the application time point. Biol Signals Recept. 1999 Jan-Apr; 8(12):132-5. https://doi.org/10.1159/000014581

11. Scheuer C. Melatonin for prevention of erythema and oxidative stress in response to ultraviolet radiation. Dan Med J. 2017 Jun; 64(6): B5358.

12. Janjetovic Z, Jarrett SG, Lee EF, Duprey C, Reiter RJ, Slominski AT. Melatonin and its metabolites protect human melanocytes against UVBinduced damage: involvement of NRF2-mediated pathways. Sci Rep.2017; 7:1274. https://doi. org/10.1038/s41598-017-01305-2

13. Janjetovic Z, Nahmias ZP, Hanna S, Jarrett SG, Kim TK, Reiter RJ, Slominski AT. Melatonin and its metabolites ameliorate ultraviolet B-induced damage in human epidermal keratinocytes. J Pineal Res. 2014; 57:90-102. https://doi. org/10.1111/jpi.12146

14. Kleszczynski K, Fischer TW. Melatonin and human skin aging. Dermatoendocrinol. 2012 Jul 1; 4(3):245-52. https://doi.org/10.4161/ derm. 22344

15. Lee JH, Moon JH, Nazim UM, Lee YJ, Seol JW, Eo SK, Lee JH, Park SY. Melatonin protects skin keratinocyte from hydrogen peroxide-mediated cell death via the SIRT1 pathway. Oncotarget. 2016 Mar 15; 7(11):12075-88. https://doi. org/10.18632/oncotarget.7679

16. Kim TK, Kleszczynski K, Janjetovic Z, Sweatman T, Lin Z, Li W, Reiter RJ, Fischer TW, Slominski AT. Metabolism of melatonin and biological activity of intermediates of melatoninergic pathway in human skin cells. FASEB J.2013; 27:2742-55. https://doi.org/10.1096/fj.12-224691

17. Bocheva G, Slominski RM, Slominski AT. Neuroendocrine Aspects of Skin Aging. Int J Mol Sci. 2019;20(11):2798

18. Burke KE. Mechanism of aging and development-A new understanding of environmental damage to the skin and prevention with topical antioxidants. Mech Ageing Dev. 2018; 172:123-30. https://doi/ org/10.1016/j.mad.2017.12.003

19. S Fischer TW, Zbytek B, Sayre RM, Apostolov EO, Basnakian AG, Sweatman TW, et al.Melatonin increases survival of $\mathrm{HaCaT}$ keratinocytes by suppressing UV-induced apoptosis. J Pineal Res. 2006; 40:18-26. https://doi.org/10.1111/j.1600079X.2005.00273.x

20. Acuña Castroviejo D, López LC, Escames G, López A, García JA, Reiter RJ. Melatonin-mitochondria interplay in health and disease. Curr Top Med Chem. 2011; 11(2):221-40. https://doi. org/10.2174/156802611794863517

21. Semak I, Naumova M, Korik E, Terekhovich V, Wortsman J, Slominski A . A novel metabolic pathway of melatonin: oxidation by cytochrome C. Biochemistry. 2005 Jul 5; 44(26):9300-7. https://doi.org/10.1021/bi050202d

22. Fischer TW, Zmijewski MA, Wortsman J, Slominski A. Melatonin maintains mitochondrial membrane potential and attenuates activation of initiator (casp-9) and effector caspases (casp-3/casp-7) and PARP in UVR-exposed HaCaT keratinocytes. J Pineal Res. 2008 May; 44(4):397-407. https://doi. org/10.1111/j.1600-079X.2007.005422.x

23. Boutin JA .Quinone reductase 2 as a promising target of melatonin therapeutic actions. Expert Opin Ther Targets. 2016; 20(3):303-17. https:// doi.org/10.1517/14728222.2016.1091882

24. Shen J, Barrios RJ, Jaiswal AK. Inactivation of the quinone oxidoreductases NQO1 and NQO2 strongly elevates the incidence and multiplicity of chemically induced skin tumors. Cancer Res. 2010 Feb 1; 70(3):1006-14. https://doi. org/10.1158/0008-5472.CAN-18-2453 
25. Kadekaro AL, Andrade LN, Floeter-Winter LM, Rollag MD, Virador V, Vieira $\mathrm{W}$, et al. MT-1 melatonin receptor expression increases the antiproliferative effect of melatonin on S-91 murine melanoma cells. J Pineal Res. 2004 Apr; 36(3):204-11. https://doi.org/10.1111/j.1600079x.2004.00119.x

26. Narita $T$, Kudo $H$. Effect of melatonin on B16 melanoma growth in athymic mice. Cancer Res. 1985 Sep; 45(9):4175-7.

27. Otálora BB, Madrid JA, Alvarez N, Vicente V, Rol MA. Effects of exogenous melatonin and circadian synchronization on tumor progression in melanoma-bearing C57BL6 mice. J Pineal Res. 2008 Apr; 44(3):307-15. https://doi.org/10.1111/ j.1600-079X.2007.00531.x

28. Cabrera J, Negrín G, Estévez F, Loro J, Reiter RJ, Quintana J. Melatonin decreases cell proliferation and induces melanogenesis in human melanoma SK-MEL-1 cells. J Pineal Res. 2010 Aug; 49(1):45-54. https://doi.org/10.1111/j.1600079X.2010.00765.x

29. Fischer TW, Zmijewski MA, Zbytek B, Sweatman TW, Slominski RM, Wortsman J, et al. Oncostatic effects of the indole melatonin and expression of its cytosolic and nuclear receptors in cultured human melanoma cell lines. Int J Oncol. 2006 Sep; 29(3):665-72. https://doi.org/10.3892/ ijo.29.3.665

30. Roberts JE, Wiechmann AF, Hu DN. Melatonin receptors in human uveal melanocytes and melanoma cells. J Pineal Res. 2000 Apr; 28(3):165-71. https://doi.org/10.1034/j.1600079x.2001.280306.x

31. Ma Z, Yang $Y$, Fan $C$, Han J, Wang $D$, Di S, et al. Melatonin as a potential anticarcinogen for nonsmall-cell lung cancer. Onco target. 2016 Jul 19; 7(29):46768-84. https://doi.org/10.18632/ oncotarget. 8776

32. Vesnushkin GM, Plotnikova NA, Semenchenko Al, Anisimov VN. Dose-dependent inhibitory effect of melatonin on carcinogenesis induced by benzo[a] pyrene in mice. J Exp Clin Cancer Res. 2006 Dec; 25(4):507-13.

33. Deriabina ON, Plotnikova NA, Anisimov VN. Melatonin and metformin inhibit skin carcinogenesis induced by benz(a)pyrene in mice. Vopr Onkol. 2010; 56(5):583-7.

34. Kumar CA, Das UN. Effect of melatonin on two stage skin carcinogenesis in Swiss mice. UN Med Sci Monit. 2000 May-Jun; 6(3):471-5.
35. Ghaderi R, Sehatbakhsh $S$, Bakhshaee $M$, Sharifzadeh GR. Urinary melatonin levels and skin malignancy. Iran J Med Sci. 2014 Jan; 39(1):64-7.

36. Fischer TW, Zmijewski MA, Zbytek B, Sweatman TW, Slominski RM, Wortsman J, et al. Oncostatic effects of the indole melatonin and expression of its cytosolic and nuclear receptors in cultured human melanoma cell lines. Int J Oncol. 2006 Sep; 29(3):665-72. https://doi.org/10.3892/ ijo.29.3.665

37. Jockers $R$, Maurice $P$, Boutin JA, Delagrange $P$ Br. Melatonin receptors, heterodimerization, signal transduction and binding sites: what's new? J Pharmacol. 2008 Jul; 154(6):1182-95.

38. Nosjean $O$, Ferro $M$, Coge $F$, Beauverger $P$, Henlin JM, Lefoulon $F$, et al. Identification of the melatonin-binding site MT3 as the quinone reductase 2. J Biol Chem. 2000 Oct 6; 275(40):31311-7. https://doi.org/10.1074/jbc. M005141200

39. Boutin JA . Quinone reductase 2 as a promising target of melatonin therapeutic actions. Expert Opin Ther Targets. 2016; 20(3):303-17. https:// doi.org/10.1517/14728222.2016.1091882

40. Shen J, Barrios RJ, Jaiswal AK. Inactivation of the quinone oxidoreductases NQO1 and NQO2 strongly elevates the incidence and multiplicity of chemically induced skin tumors. Cancer Res. 2018 Nov 1; 78(21):6345. https://doi. org/10.1158/0008-5472.CAN-18-2453

41. Ahn KS, Gong X, Sethi G, Chaturvedi MM, Jaiswal AK, Aggarwal BB. Deficiency of NRH:quinone oxidoreductase 2 differentially regulates TNF signaling in keratinocytes: up-regulation of apoptosis correlates with down-regulation of cell survival kinases. Cancer Res. 2007 Oct 15; 67(20):10004-11. https://doi.org/10.1158/00085472.CAN-07-2213

42. Ma $Q$, Reiter RJ, Chen Y. Role of melatonin in controlling angiogenesis under physiological and pathological conditions. Angiogenesis. 2020 May;23(2):91-104. https://doi.org/10.1007/ s10456-019-09689-7

43. Brzozowska I, Strzalka M, Drozdowicz D, Konturek SJ, Brzozowski T. Mechanisms of esophageal protection, gastroprotection and ulcer healing by melatonin. implications for the therapeutic use of melatonin in gastroesophageal reflux disease (GERD) and peptic ulcer disease. Curr Pharm Des. 2014: 20(30):4807-15. https://doi.org/2174/1381 612819666131119110258 
44. Lee SJ, Jung YH, Oh SY, Yun SP, Han HJ. Melatonin enhances the human mesenchymal stem cells motility via melatonin receptor 2 coupling with Gaq in skin wound healing. J Pineal Res. 2014 Nov; 57(4):393-407. https://doi.org/10.1111/jpi.12179

45. Pugazhenthi K, Kapoor M, Clarkson AN, Hall I, Appleton I. Melatonin accelerates the process of wound repair in full-thickness incisional wounds. J Pineal Res. 2008 May; 44(4):387-96. https://doi. org/10.1111/j.1600-079X.2007.00541.x

46. Romić MD, Klarić MŠ, Lovrić J, Pepić I, CetinaČižmek B, Filipović-Grčić J, et al. Melatonin-loaded chitosan/Pluronic ${ }^{\circledR}$ F127 microspheres as in situ forming hydrogel: An innovative antimicrobial wound dressing. Eur J Pharm Biopharm. 2016 Oct; 107:67-79. https://doi.org/10.1016/j. ejpb.2016.06.013

47. Song R, Ren L, Ma H, Hu R, Gao H, Wang L, et al. Melatonin promotes diabetic wound healing in vitro by regulating keratinocyte activity. J Transl Res. 2016; 8(11):4682-93

48. Schallreuter $K U$, Bahadoran $P$, Picardo $M$, Slominski A, Elassiuty $Y E$, Kemp EH, et al. Vitiligo pathogenesis: autoimmune disease, genetic defect, excessive reactive oxygen species, calcium imbalance, or what else? Exp Dermatol. 2008 Feb; 17(2):139-40. https://doi.org/10.1111/j.16000625.2007.00666_1.x

49. Schallreuter KU, Salem MA, Gibbons NC, Martinez A, Slominski R, Lüdemann J, et al. Blunted epidermal L-tryptophan metabolism in vitiligo affects immune response and ROS scavenging by Fenton chemistry, part 1: Epidermal $\mathrm{H} 2 \mathrm{O} 2 /$ ONOO(-)-mediated stress abrogates tryptophan hydroxylase and dopa decarboxylase activities, leading to low serotonin and melatonin levels. FASEB J. 2012 Jun; 26(6):2457-70. https://doi. org/10.1096/fj.11-197137

50. Hamadi SA, Mohammed MM, Aljaf AN, Abdulrazak A. The role of topical and oral melatonin in management of melasma patients. J Arab Univ Basic Appl Sci. 2009; 8:30-42.

51. Juhasz MLW, Levin MK. The role of systemic treatments for skin lightening. J Cosmet Dermatol. 2018 Dec;17(6):1144-57. https://doi. org/10.1111/jocd.12747

52. Fischer TW, Slominski A, Tobin DJ and Paus R. Melatonin and the hair follicle. J Pineal Res. 2008; 44(1): 1-15. https://doi.org/10.1111/j.1600079X.2007.00512.x
53. Haslam IS, Jadkauskaite L, Szabó IL, Staege $S$, Hesebeck-Brinckmann J, Jenkins $G$, et al. Oxidative Damage Control in a Human (Mini-) Organ: Nrf2 Activation Protects against Oxidative Stress-Induced Hair Growth Inhibition. J Invest Dermatol. 2017 Feb; 137(2):295-304. https://doi. org/10.1016/j.jid.2016.08.035

54. Kobayashi $H$, Kromminga A, Dunlop TW, Tychsen $B$, Conrad F, Suzuki N, et al. A role of melatonin in neuroectodermal-mesodermal interactions: the hair follicle synthesizes melatonin and expresses functional melatonin receptors. FASEB J. 2005 Oct; 19(12):1710-2. https://doi.org/10.1096/ fj.04-2293fje

55. Al-Nuaimi $Y$, Hardman JA, Bíró $T$, Haslam IS, Philpott MP, Tóth BI, et al. A meeting of two chronobiological systems: circadian proteins Period 1 and BMAL1 modulate the human hair cycle clock. J Invest Dermatol. 2014 Mar; 134(3):61019. https://doi.org/10.1038/jid.2013.366

56. Hardman JA, Tobin DJ, Haslam IS, Farjo N, Farjo B, Al-Nuaimi $\mathrm{Y}$, et al. The peripheral clock regulates human pigmentation. J Invest Dermatol. 2015 Apr; 135(4):1053-64. https://doi.org/10.1038/ jid.2014.442

57. Carrillo-Vico A, Lardone PJ, Alvarez-Sánchez N, Rodríguez-Rodríguez A, Guerrero JM. Melatonin: buffering the immune system. Int J Mol Sci. 2013 Apr 22; 14(4):8638-83. https://doi.org/10.3390/ ijms14048638

58. Ren W, Liu G, Chen S, Yin J, Wang J, Tan B, et al. Melatonin signaling in $T$ cells: Functions and applications. J Pineal Res. 2017 Apr; 62(3). e12394. https://doi.org/10.1111/jpi.12394

59. Kartha LB, Chandrashekar L, Rajappa M, Menon V, Thappa DM, Ananthanarayanan PH. Serum melatonin levels in psoriasis and associated depressive symptoms. Clin Chem Lab Med. 2014 Jun; 52(6): e123-5. https://doi.org/10.1515/cclm2013-0957

60. Calvo JR, Maldonado MD. The role of melatonin in autoimmune and atopic diseases. AIMS Mol Sci.2016; 3:158-86. https://doi.org/10.3934/ molsci.2016.2.158

61. Marseglia L, Cuppari C, Manti S, D'Angelo G, Salpietro C, Reiter RJ, et al. Atopic dermatitis: melatonin as potential treatment. J Biol Regul Homeost Agents. 2015 Apr-Jun; 29(2 Suppl 1):142-9.

62. Farez MF, Mascanfroni ID, Méndez-Huergo SP, Yeste A, Murugaiyan G, Garo LP, et al. Melatonin 
Contributes to the Seasonality of Multiple Sclerosis Relapses. J Cell. 2015 Sep 10; 162(6):1338-52. https://doi.org/10.1016/j.cell.2015.08.025

63. Sanchez-Barcelo EJ, Rueda N, Mediavilla MD, Martinez-Cue C, Reiter RJ. Clinical Uses of Melatonin in Neurological Diseases and Mental and Behavioural Disorders. Curr Med Chem. 2017 Nov 20;24(35):3851-78. https://doi.org/10.2174/ 0929867324666170718105557

64. AokiK,ZhaoK, Yamazaki F, Sone R, Alvarez GE, Kosiba $W A$, et al. Exogenous melatonin administration modifies cutaneous vasoconstrictor response to whole body skin cooling in humans. J Pineal Res. 2008 Mar; 44(2):141-8. https://doi.org/10.1111/ j.1600-079X.2007.00501.x

65. Romero $A$, Ramos E, López-Muñoz F, De Los Ríos C, Egea J, Gil-Martín E, et al. Toxicology of Blister Agents: Is Melatonin a Potential Therapeutic
Option? Diseases. 2021 Apr 10;9(2):27. https:// doi.org/10.3390/diseases 9020027

66. Reiter RJ, Abreu-Gonzalez P, Marik PE, DominguezRodriguez A. Therapeutic Algorithm for Use of Melatonin in Patients With COVID-19. Front Med (Lausanne). 2020 May 15; 7:226. https://doi. org/10.3389/fmed.2020.00226

67. Shneider A, Kudriavtsev A, Vakhrusheva A. Can melatonin reduce the severity of COVID-19 pandemic? Int. Rev. Immunol. 2020;39(4):153-62. https://doi.org/10.1080/08830185.2020.175628 4

68. Bahrampour Juybari $\mathrm{K}$, Pourhanifeh $\mathrm{MH}$, Hosseinzadeh A, Hemati K, Mehrzadi S. Melatonin potentials against viral infections including COVID-19: Current evidence and new findings. Virus Res. 2020; 287:198108. https://doi. org/10.1016/j.viruses.2020.198108 